Supporting Information for

\title{
A Lipophilic Pt(IV) Oxaliplatin Derivative Enhances Antitumor activity
}

Aiman Abu Ammar, Raji Raveendran, Dan Gibson, Taher Nassar and Simon Benita*

The Hebrew University of Jerusalem, Institute for Drug Research of the School of Pharmacy, Faculty of Medicine, POB 12065, Jerusalem, 9112100, Israel

E-mail: simonb@ekmd.huji.ac.il

\section{Contents:}

Table S1. $\mathrm{IC}_{50}(\mu \mathrm{M})$ and resistant factor values for oxaliplatin (OXA) and $\mathbf{1}$ against A2780, A2780-cisR cell lines

Table S2. The $\mathrm{IC}_{50}$ values of OXA, $\mathbf{1}$, and $\mathbf{2}$ in two cancer cell lines, used in the efficacy animal studies

Figure S1. Cytotoxic activity of OPA NPs (2) compared to OXA and 1, in SKOV-3 cell line

Figure S2. Representative measurement of 1 micelles formed when $\mathbf{1}$ solution in a cremophor EL/ ethanol mixture $(1: 1, \mathrm{v} / \mathrm{v})$

Table S3. Freeze drying conditions for 2

Table S4. Mean particle diameter and zeta potential values of 2 before and after lyophilization

Figure S3. TEM micrograph of uranyl acetate negatively stained 2 lyo-NPs following 4 weeks storage

Figure S4. NMR, ESI-MS spectra and HPLC chromatogram of 1 
Table S1. $\mathrm{IC}_{50}(\mu \mathrm{M})$ and resistant factor values for oxaliplatin (OXA) and a $\mathrm{Pt}(\mathrm{IV})$ derivative of OXA with one axial acetate and one axial palmitate ligand (compound 1) against A2780, A2780-cisR cell lines.

\begin{tabular}{cccc}
\hline \multirow{2}{*}{ Compound } & \multicolumn{2}{c}{$\mathbf{I C}_{\mathbf{5 0}}(\boldsymbol{\mu M})^{[\mathbf{a}]}$} & \\
\cline { 2 - 3 } & $\mathbf{A 2 7 8 0}$ & $\mathbf{A 2 7 8 0}-\mathbf{c i s R}$ & $\mathbf{R F}^{[\mathbf{b}]}$ \\
\hline Cisplatin & $0.94 \pm 0.04$ & $14.6 \pm 1.44$ & 15.53 \\
OXA & $0.78 \pm 0.02$ & $4.1 \pm 0.25$ & 5.21 \\
$\mathbf{1}$ & $0.36 \pm 0.01$ & $0.34 \pm 0.01$ & 0.93 \\
\hline
\end{tabular}

${ }^{\text {[a] }} \mathrm{IC}_{50}$ values are drug concentrations required for $50 \%$ cell death and are the means $\pm \mathrm{SD}$ of three independent experiments. ${ }^{[b]} \mathrm{RF}$ (resistance factor) is the ratio of the $\mathrm{IC}_{50}$ value in the resistant cell line to that in the parent cell line.

Table S1 depicts the results from experiments comparing $\mathrm{IC}_{50}$ values for resistant and sensitive cell lines for cisplatin, Oxaliplatin and $\mathbf{1}$. It can be seen that $\mathbf{1}$ is active against sensitive and resistant cell lines at almost the same $\mathrm{IC}_{50}$ values whereas Oxaliplatin and cisplatin need 5 fold and 15 fold concentration, respectively, to elicit the same activity in resistant cells as in the sensitive cell line.

Table S2. The $\mathrm{IC}_{50}$ values of OXA, 1, and 2 in two cancer cell lines, used in the efficacy animal studies, following $120 \mathrm{~h}$ incubation. Values are the means $\pm \mathrm{SD}$ obtained from three independent experiments.

\begin{tabular}{cccc}
\hline \multirow{2}{*}{ Cell line } & & $\mathbf{I C}_{\mathbf{5 0}}(\boldsymbol{\mu M})$ & \\
\cline { 2 - 4 } & $\mathbf{O X A}$ & $\mathbf{1}$ & $\mathbf{2}$ \\
\hline SKOV3-luc-D3 & $115.87 \pm 9.08$ & $0.61 \pm 0.02$ & $2.36 \pm 0.28$ \\
HCT 116-luc2 & $2.30 \pm 1.08$ & $0.37 \pm 0.02$ & $0.40 \pm 0.02$ \\
\hline
\end{tabular}

It can be noted from the data presented in TableS2 that SKOV3-luc-D3 is much more sensitive to $\mathbf{1}$ and 2 than OXA. SKOV3-luc-D3 is a luciferase expressing cell line that was derived from SKOV-3 human ovarian carcinoma cells by stable transfection of the North American Firefly Luciferase gene expressed from the CMV promoter. Apparently, the manipulation renders the cell line more resistant to OXA since a 2 fold concentration was needed to reach the $\mathrm{IC}_{\mathbf{5 0}}$ value activity for the native cell line (115.87 \pm 9.08 versus $58.26 \pm 6.34 \mu \mathrm{M}$ respectively). In contrast the luciferase expressing cell line was not more resistant to $\mathbf{1}$ than the native cell as can be deduced from the results presented in Table 1 of the manuscript compared to the value presented in Table S2. Finally, it can be noted that HCT 116-luc2 was more sensitive to OXA than the other respective line but $\mathbf{1}$ and $\mathbf{2}$ were more potent than OXA as deduced from the data presented in Table S2. 


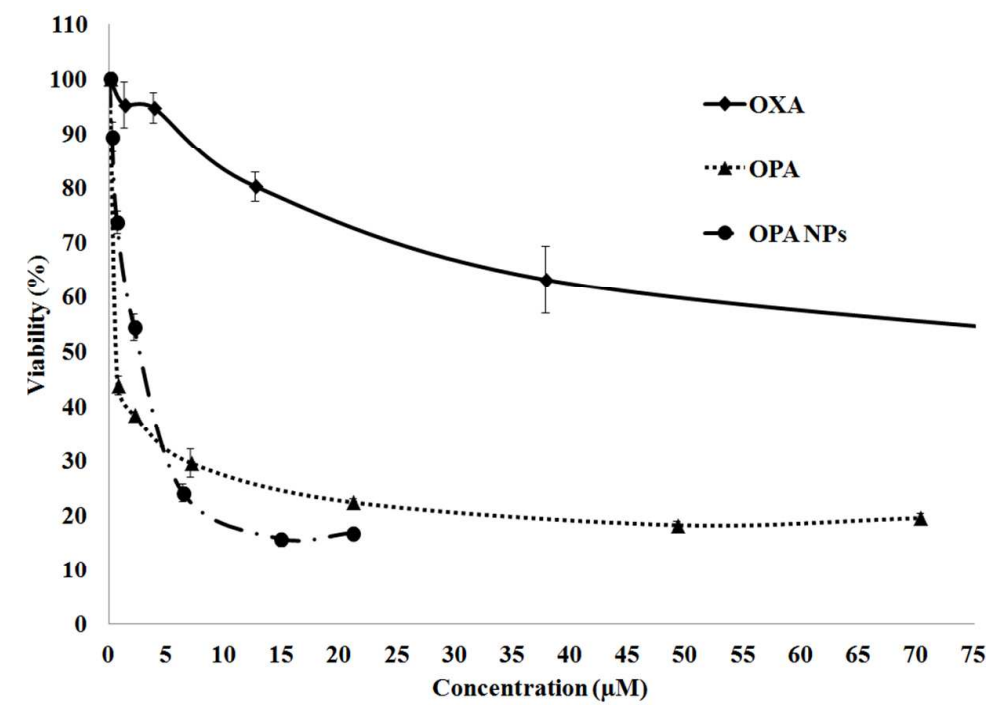

Figure S1. Cytotoxic activity of OPA NPs (2) compared to OXA and 1, in SKOV-3 cell line.

The data depicted in Fig S1 confirm the trend already observed in the SKOV3-luc-D3.

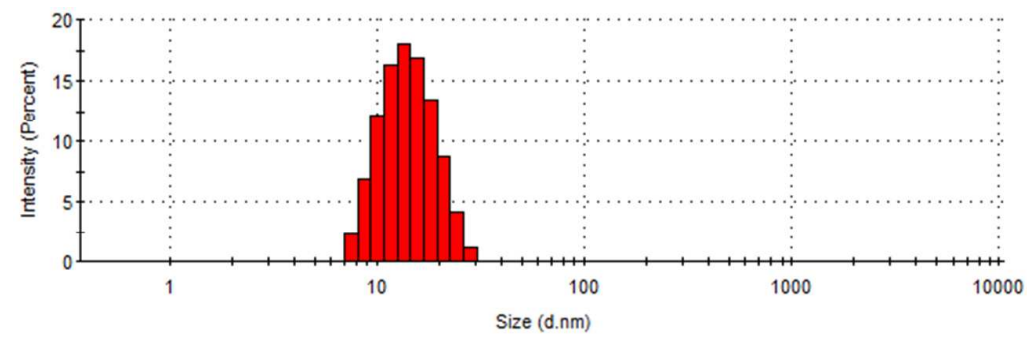

Figure S2. Representative measurement of 1 micelles formed when 1 solution in a cremophor EL/ ethanol mixture $(1: 1, \mathrm{v} / \mathrm{v})$. The injected volume of $200 \mu$ l contained $10 \%$ of OPA stock solution.

The data exhibited in Fig S2 using DLS (diffraction light scattering) technique confirm the formation of the micelle-like 1 NPs.

\section{Lyophilization of 2}

Five types of sugars were evaluated as cryo- and lyoprotectants for the freeze-drying process of OPA NPs: sucrose, $(+)$ trehalose, D (-) mannitol, xylitol, and the macrocyclic oligosugar hydroxypropyl- $\beta$-cyclodextrin (HP $\beta C D$ ). Different sugar concentrations were utilized to find the most suitable concentration for the drug-loaded NPs lyophilization. The NP suspension was freeze-dried using an Epsilon 2-6d Martin Christ lyophilizer (Gef., Germany) to obtain a dry powder. The conditions of the freeze-drying of the various formulations are depicted in Table S3. 
Table S3. Freeze drying conditions for 2.

\begin{tabular}{ccccc}
\hline Step \# & Process & $\begin{array}{c}\text { Duration } \\
(\mathbf{h})\end{array}$ & Temperature $\left({ }^{\circ} \mathbf{C}\right)$ & Vacuum (mBar) \\
\hline 1 & Loading & $0: 00$ & 20 & 0 \\
2 & Freezing & $1: 00$ & -35 & 0 \\
3 & & $1: 00$ & -35 & 1.03 \\
4 & Sublimation & $0: 15$ & -35 & 1.03 \\
5 & & $0: 15$ & -20 & 1.03 \\
6 & & $0: 10$ & -10 & 1.03 \\
7 & & $4: 00$ & 0 & 1.03 \\
8 & & $5: 00$ & 20 & 0.94 \\
9 & Secondary drying & $5: 00$ & 20 & 0.001 \\
Total duration & & $16: 40$ & & \\
\hline
\end{tabular}

It was found that only sucrose was able to properly cryoprotect the NPs which elicited the same property values before lyophilization and after reconstitution of the colloidal dispersion following lyophilization ( freeze-drying) of the NPs as can be seen in Table S4.

Table S4. Mean particle diameter and zeta potential values of $\mathbf{2}$ before and after lyophilization and reconstitution of the dispersion over 1 day, 4 weeks and 16 weeks.

\begin{tabular}{|c|c|c|c|c|c|}
\hline Formulation & $\begin{array}{l}\text { OPA conc. } \\
(\mathrm{mg} / \mathrm{mL})\end{array}$ & $\begin{array}{c}\text { Mean diameter } \\
(\mathbf{n m})\end{array}$ & PDI value & $\begin{array}{c}\text { Zeta } \\
\text { potential } \\
\mathrm{mV}\end{array}$ & $\begin{array}{l}\text { Ratio } \\
\text { (Sf/Si ) }\end{array}$ \\
\hline 2 & 2.6 & $146.3 \pm 1.6$ & $0.1 \pm 0.01$ & $-49.3 \pm 1.1$ & - \\
\hline 2 lyo-NPs $^{[\mathrm{a}]}$ & 2.6 & $196.0 \pm 6.2$ & $0.1 \pm 0.02$ & $-46.6 \pm 0.6$ & 1.34 \\
\hline 2 lyo-NPs, $4^{\circ} C^{[b]}$ & 2.6 & $197.1 \pm 2.1$ & $0.1 \pm 0.02$ & $-51.7 \pm 0.8$ & 1.34 \\
\hline 2 lyo-NPs, $-20^{\circ} C^{[c]}$ & 2.6 & $190.1 \pm 2.2$ & $0.1 \pm 0.01$ & $-41.6 \pm 2.3$ & 1.29 \\
\hline
\end{tabular}

${ }^{[\mathrm{a}]}$ Reconstitution after 1 day. ${ }^{[\mathrm{b}]}$ Reconstitution after 4 weeks. ${ }^{[\mathrm{c}]}$ Reconstitution after 16 weeks. Values are the means $\pm \operatorname{SD}(n=3)$. 


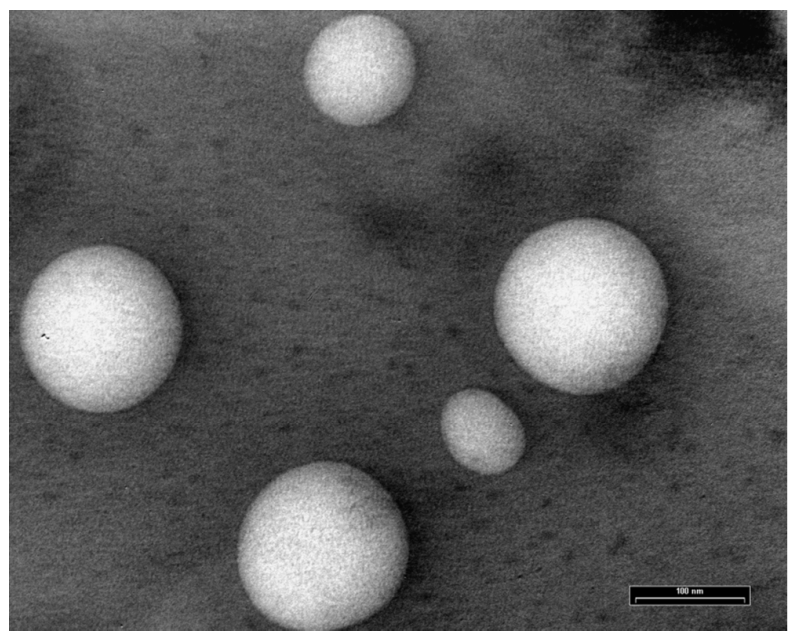

Figure S3. TEM micrograph of uranyl acetate negatively stained 2 lyo-NPs following 4 weeks storage at $4^{\circ} \mathrm{C}$ and reconstitution of the aqueous colloidal dispersion.

It can be observed that following lyophilization and reconstitution of the aqueous dispersion no aggregation of the NPs was detected and individual NPs were again formed as depicted from the representative sample in Fig S3

\section{Characterization of 1}

(A)

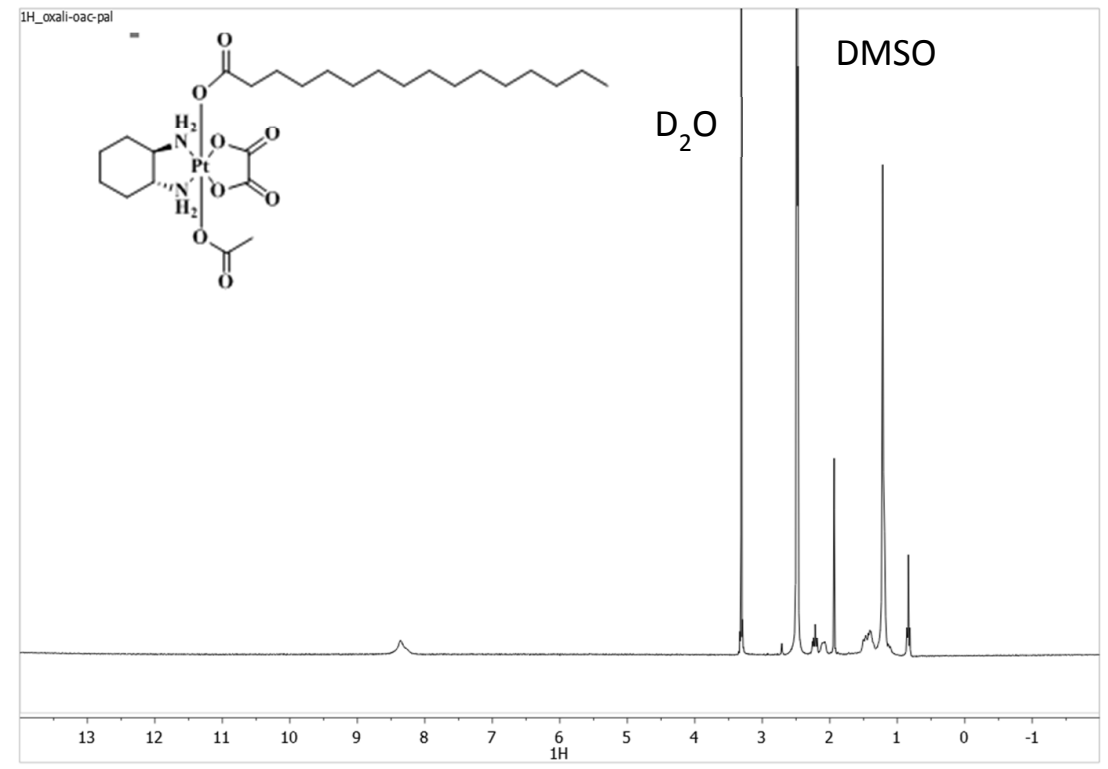


(B)

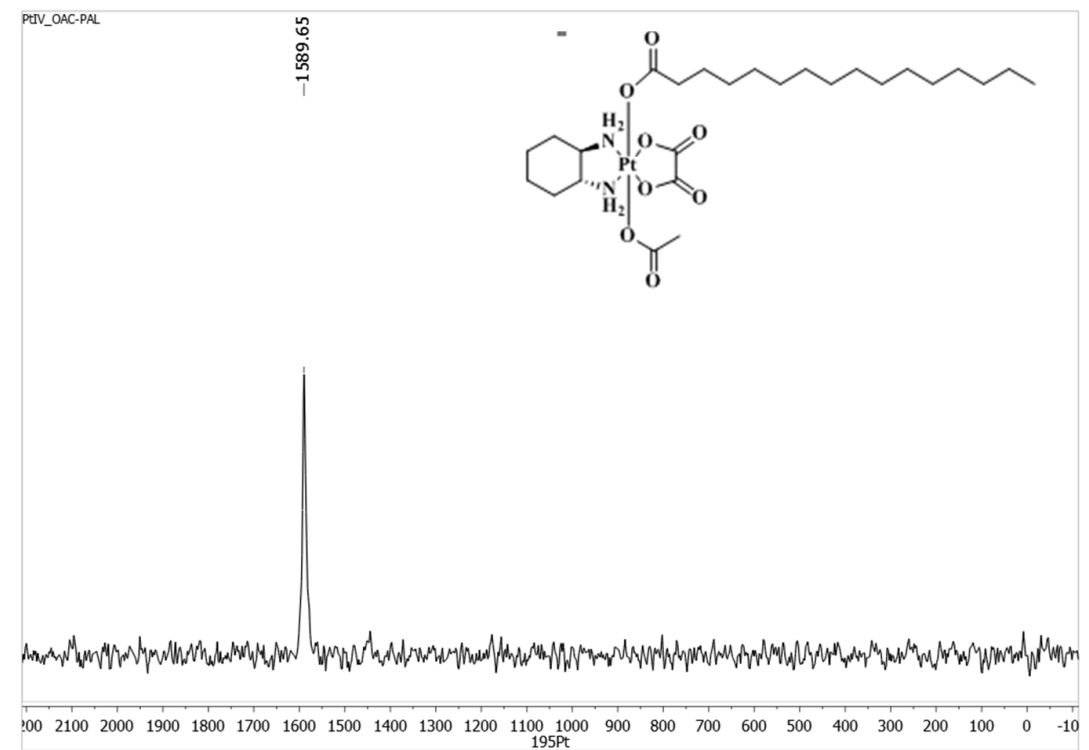

(C)

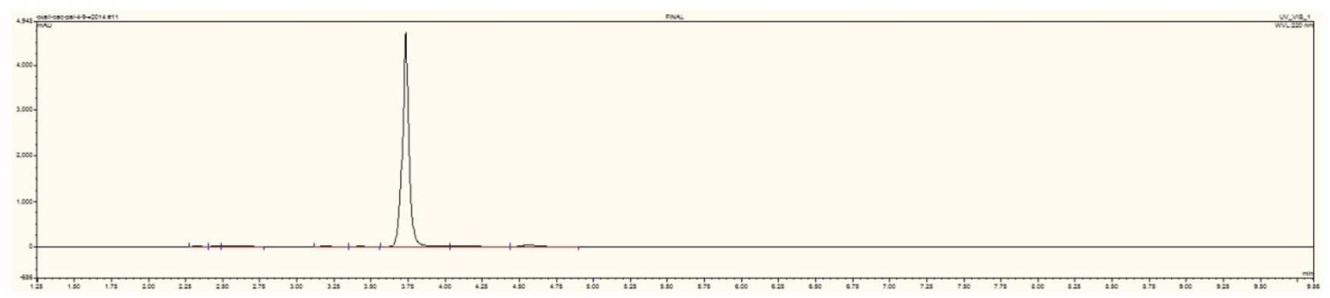

(D)

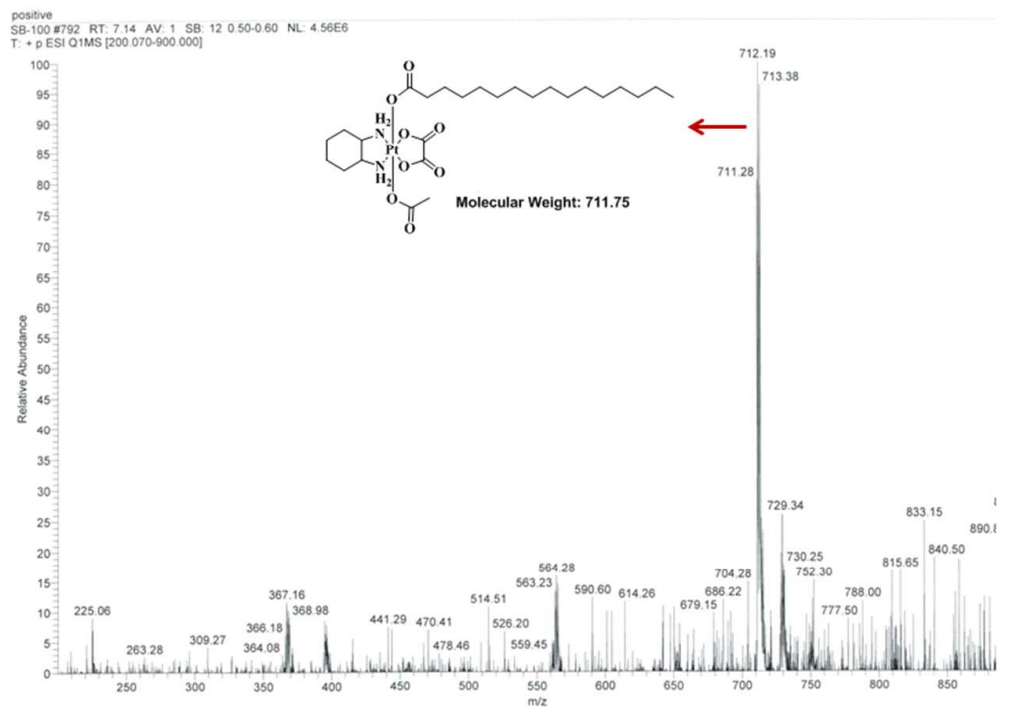


Figure S4. NMR, ESI-MS spectra and HPLC chromatogram of 1 . (A) ${ }^{1} \mathrm{H}$ NMR spectrum of 1 in DMSO- $\mathrm{d}_{6}$. (B) ${ }^{195} \mathrm{Pt}$ NMR spectrum of $\mathbf{1}$ in DMF. (C) HPLC chromatogram of $\mathbf{1}$ in $100 \%$ Acetonitrile at $220 \mathrm{~nm}$. (D) ESI-MS of 1 in positive ion mode. 